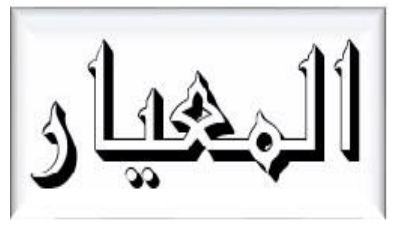

Al Mi'yar

Vol. 4, No. 1, April 2021

P-ISSN: 2620-6749, E-ISSN: 2620-6536

DOI: $10.35931 / a m . v 4 i 1.524$

Naskah diterima: 15-02-2021

Direvisi: 22-03-2021

Disetujui: 05-04-2021

\title{
ISU DAN TREN PENELITIAN PENGEMBANGAN BAHAN AJAR BAHASA ARAB TAHUN 2017-2020
}

\author{
Nurul Aini Baarid', Kamal Yusuf ${ }^{2}$ \\ Uin Sunan Ampel Surabaya, Jawa Timur, Indonesia \\ E-mail: Nurulainibaarid@gmail.com, kamalinev@gmail.com
}

\begin{abstract}
The aim of this study is to determine the research tren for the development of Arabic teaching materials in year 2017-2020 of Postgraduate students at UIN Sunan Ampel in Surabaya whether this tren is consistent with the development of Industrial Revolution 4.0, which is linked by a system that unites the real and virtual world, or vice versa. The research method used is descriptive analysis research by collecting library data, recording and processing literacy data related to these issues. The results showed that research on the development of Arabic teaching materials to improve four language skills was ranked first as the most emerging research topic with a percentage of $0.6 \%$, secondly research on the design of Arabic teaching materials with a percentage of $0.08 \%$, third research on the Arabic learning curriculum for comparative studies and its development with a percentage of $0.08 \%$, then research on the pedagogical and professional competences of teachers and their effects on student achievement with a percentage of $0.07 \%$, then technology-based research for learning Arabic with a value 0.07\%, research on the influence of the language environment by $0.04 \%$, then research on the development of an assessment instrument of $0.02 \%$ and research on strategies, media, and methods of learning Arabic as well as book analysis research respectively ranked last with a percentage of $0.01 \%$ as the least frequent research topic.
\end{abstract}

Keywords: Development research, Teaching materials, Arabic language 


\section{PENDAHULUAN}

Generasi milenial disebut juga dengan generasi era digital, generasi yang lahir antara tahun 1980 sampai tahun $2000 .^{3}$ Generasi tersebut sangat akrab dengan teknologi informasi dan komunikasi, kemajuan teknologi informasi dan komunikasi sangat berpengaruh dalam dunia pendidikan, begitu juga dalam mengembangkan bahan ajar bahasa Arab di Indonesia. Hal ini menunjang guru untuk mampu mengaktualisasikan diri dan berinovasi serta mempunyai daya kreatifitas dalam proses pembelajaran dan mengembangkan bahan ajar. ${ }^{4}$ Akan tetapi dalam pelaksanannya belum sepenuhnya bisa diterima oleh guru, masih banyak guru yang belum bisa mengoperasikan secara penuh teknologi, informasi dan komunikasi dan belum bisa mengikuti alur digital. ${ }^{5}$ Di sisi lain semua aktivitas yang dilakukan peserta didik milenial tidak terlepas dari dunia digital (internet), mayoritas diantaranya belajar mandiri melalui platform online. Semua hal bisa diakses oleh peserta didik milenial dimulai dari pengoperasian situs pencarian, jejaring sosial dan media sosial lainnya. ${ }^{6}$ Itulah sebabnya, pada saat ini guru dituntut untuk terus berubah dan belajar. ${ }^{7}$ Untuk itu, dalam pembelajaran bahasa Arab guru sepatutnya tidak mengandalkan satu jenis bahan ajar agar siswa aktif dalam belajar, tetapi diperlukan suatu jenis dan ragam yang berbeda dalam menggunakan bahan ajar, serta mampu untuk mengembangkan bahan ajar sebagai sumber belajar. Penelitian merupakan usaha untuk mendapatkan, mengembangkan dan menjalankan verifikasi keadaan yang sesungguhnya terhadap suatu peristiwa atau pengetahuan

${ }^{3}$ Akhsan dan Ahmadi Muhammadiyah, "Model Belajar dan Pembelajaran Bahasa Arab Generasi Milenial," Lahjah Arabiyah: Jurnal Bahasa Arab dan Pendidikan Bahasa Arab 1, no. 2 (2020): h. 3.

${ }^{4}$ Darisy Syafaah, "Inovasi Pembelajaran Bahasa Arab Pada Prodi Bahasa dan Sastra Arab IAIN Tulungagung dalam Menghadapi Tantangan Era Industri 4.0," Prosiding Konferensi Nasional Bahasa Arab V Malang: Jurusan Sastra Arab Fakultas Sastra Universitas Negeri Malang", (2019): h. 2-3.

${ }^{5}$ Erwin Widiasworo, Guru Ideal di Era Digital: Panduan Pemanfaatan Teknologi untuk Guru Masa Kini, (Yogyakarta: Noktah, 2019), h. 16.

6 Mahyuddin Barni, "Tantangan Pendidik di Era Milenial," Transformatif: Jurnal Islamic Studies 3, no. 01 (2019): h. 6.

7 J. Sumardianta dan Wahyu Kris, Mendidik Generasi Z dan A Marwah Era Milenial Tuah Generasi Digital, (Jakarta: PT Grasindo, 2018), h. 5. 
dengan menggunakan metode ilmiah. ${ }^{8}$ Kegiatan penelitian secara umum bertujuan untuk menemukan, mengembangkan / menguji kebenaran suatu pengetahuan. ${ }^{9}$

Penelitian tentang pengembangan bahan ajar bahasa Arab di era digital ini diantaranya ialah penelitian tentang pengembangan materi pembelajaran berbasis teknologi (cd interaktif) meningkatkan kemampuan mendengar dan berbicara siswa, hubungan antara profesionalisme guru dan lingkungan bahasa Arab terhadap maharah kalam santri, pengembangan penggunaan media pembelajaran untuk meningkatkan keterampilan berbicara tentang tema-tema nahwu dari kitab al-arabiyah al-mu'ashirah, pengembangan bahan ajar bahasa Arab untuk meningkatkan kemampuan bahasa untuk siswa dan lain sebagainya. Hasil dari penelitian ini bahwa tingkat profesionalisme guru mempengaruhi dalam pengembangan bahan ajar bahasa Arab dan dengan menggunakan pendekatan media pembelajaran dapat meningkatkan stimulus dan pemahaman yang lebih bagi peserta didik.

Dari penelitian pengembangan yang telah dilakukan, belum ada sejauh ini yang membahas dan mengklasifikasikan tentang tren penelitian pengembangan bahan ajar bahasa Arab mahasiswa Pascasarjana UIN Sunan Ampel Surabaya. Hal ini perlu dilakukan karena menurut (Ahmad: 2008), kelompok literasi era industri 4.0 terbagi menjadi 3, yaitu: a) literasi data, b) literasi teknologi dan c) literasi manusia. ${ }^{1}$

Berdasarkan latar belakang tersebut, penelitian ini bertujuan untuk mengetahui tren penelitian pengembangan bahan ajar bahasa Arab mahasiswa Pascasarjana UIN Sunan Ampel Surabaya dalam empat tahun terakhir sejak tahun 2017 hingga 2020.

8 Saipul dan Bahruddin, Metode Penelitian Kuantitatif Aplikasi dalam Pendidikan, (Yogyakarta: Deepublish CV Budi Utama, 2014): h. 3.

9 Slamet dan Aglis, Metode Riset Penelitian Kuantitatif, Penelitian di Bidang Manajemen, Teknik, Pendidikan dan Eksperimen, (Yogakarta: CV Budi Utama, 2020), h. 3.

1 Yusnaini dan Slamet, "Era Revolusi Industri 4.0: Tantangan dan Peluang dalam Upaya Meningkatkan Literasi Pendidikan." Prosiding seminar nasional pendidikan Program Pascasarjana Universitas PGRI Palembang, 2019): h. 9. 


\section{METODE PENELITIAN}

Metode yang digunakan dalam penelitian ini adalah metode analisis deskriptif yang bertujuan untuk menggambarkan data secara sistematis dan faktual serta menghubungkan antar variabel dengan cara menghimpun, mengolah data dan menganalisis serta menginterpretasikannya. ${ }^{11}$ Untuk mendapatkan beberapa jenis data dari sumber data, peneliti menggunakan teknik pengumpulan data berupa pengumpulkan data pustaka, mencatat dan mengolah data literasying terkait isu-isu tersebut. ${ }^{12}$

Tahapan pertama dari penelitian ini adalah penulis mencari sumber data dari Repository UIN Sunan Ampel Surabaya, kemudian menghimpun dan mengumpulkan keseluruhan topik penelitian tugas akhir (thesis) mahasiswa Pendidikan Bahasa Arab Pascasarjana UIN Sunan Ampel Surabaya sejak tahun 2017 hingga 2020. Selanjutnya penulis mentabulasikan data-data tersebut dalam satu tabel di Microsoft excel, kemudian data tersebut dikategorikan pada subtema, setelah data terkumpul pada kategori yang sama, selanjutnya penulis menghitung persentasi dari hasil pengkategorian dan yang terakhir penulis menganalisis dan menginterpretasikan data hasil tersebut.

\section{HASIL DAN PEMBAHASAN}

\section{Klasifikasi Topik}

Dari sekian tabulasi penelitian pengembangan bahan ajar bahasa Arab mahasiswa Pascasarjana UIN Sunan Ampel Surabaya Prodi Pendidikan Bahasa Arab tahun ajar 2017 hingga tahun 2020, berdasarkan data yang diperoleh terdapat dua kategori penelitian, yaitu penelitian pengembangan bahan ajar dan penelitian perbandingan, dikategorikan sebagai berikut:

a. Penelitian pengembangan bahan ajar diperoleh sebanyak 60 judul penelitian, meliputi:

\footnotetext{
11

Devinisi

Metode

Analisis

Deskr iptif adalah:https://elib.unikom.ac.id/files/disk1/699/ibptunikompp-gdl-fahmyfadil-34933-8fahmy un-i.pdf (diakses pada 5 januari 2021).
}

12 Hesti, Venia, Rofiatus dan Danial, "Video Based Learning Sebagai Trend Media Pembelajaran di Era 4.0." Tarbiyatuna: Jurnal Pendidikan Ilmiah 5, no. 1 (2020): h. 1. 
1. Penelitian pengembangan bahan ajar / materi ajar untuk 4 keterampilan berbahasa, keterampilan membaca, menulis, mendengar dan berbicara.

2. Pengembangan butir soal bahan ajar dan TOAFL untuk siswa dan mahasiswa pendidikan bahasa Arab.

3. Penyusunan buku lembar kerja siswa (LKS) materi bahasa Arab.

b. Penelitian pengembangan instrument buku ajar bahasa Arab diperoleh 2 judul penelitian, meliputi:

1. Pengembangan instrument penilaian autentik berbasis kurikulum 2013 untuk keterampilan berbahasa.

c. Penelitian pengembangan media pembelajaran bahan ajar bahasa Arab berbasis teknologi diperoleh sebanyak 7 judul, meliputi:

1. Pengembangan media pembelajaran Lectora, cd interaktif, autoplay dan quiz creator, articulate studio, learning vlog, comic strips serta program wondershare quiz creator untuk meningkatkan 4 keterampilan berbahasa (membaca, menulis, mendengar dan berbicara).

d. Penelitian pengembangan berbasis desain bahan ajar / materi ajar bahasa Arab diperoleh sebanyak 8 judul, meliputi:

1. Desain penggunaan gambar dan semiotik visual pada kitab bahasa Arab.

2. Desain lembar kerja siswa (LKS) materi ajar bahasa Arab berdasarkan analisis kesalahan.

3. Desain materi ajar balaghah.

4. Desain perangkat lunak ponsel android untuk kosakata bahasa Arab berdasarkan pembelajaran mandiri.

5. Desain bahan ajar keterampilan berbahasa berbasis muatan lokal / budaya lokal, dan

6. Desain materi nahwu dengan contoh ayat-ayat al-qur'an.

e. Penelitian terkait kompetensi diperoleh sebanyak 7 judul, meliputi:

1. Pengaruh kompetensi pedagogik dan kompetensi profesional dosen dan guru terhadap prestasi siswa dan mahasiswa serta terhadap prestasi keterampilan berbicara siswa dan mahasiswa dalam berbahasa Arab. 
f. Penelitian pengembangan terkait kurikulum diperoleh sebanyak 8 judul, meliputi:

1. Pengembangan kurikulum bahan ajar / materi ajar bahasa Arab untuk meningkatkan 4 keterampilan berbahasa (membaca, menulis, mendengar dan berbicara).

2. Studi komparatif kurikulum antar Pondok Pesantren.

3. Analisis deskriptif evaluatif kurikulum pendidikan bahasa Arab berdasarkan perspektif pragmatik dan fungsional.

g. Penelitian terkait analisis diperoleh sebanyak 1 judul, yaitu:

1. Analisis E-Book antara Modern Standard Arabic dan Arabic Online.

h. Penelitian terkait metode pembelajaran bahasa Arab diperoleh sebanyak 1 judul, yaitu:

1. Studi komparatif metode pembelajaran keterampilan bahasa Arab.

i. Penelitan perbandingan terkait pengaruh lingkungan berbahasa antar Pondok Pesantren terhadap 4 keterampilan berbahasa siswa (membaca, menulis, mendengar dan berbicara) diperoleh sebanyak 4 judul penelitian.

\section{Kuantifikasi Klasifikasi Topik}

Dari tabulasi penelitian pengembangan bahan ajar bahasa Arab mahasiswa Pascasarjana Pendidikan Bahasa Arab UIN Sunan Ampel Surabaya periode 2017- 2020, diperoleh persentasi sebagai berikut: ${ }^{13}$ 2020).

13 Digilib UIN Sunan Ampel Surabaya.www.digilib.uinsby.ac.id (diakses pada 16 Oktober 
Nurul Aini Baarid \& Kamal Yusuf: Isu Dan Tren Penelitian Pengembangan Bahan Ajar Bahasa Arab Tahun 2017-2020

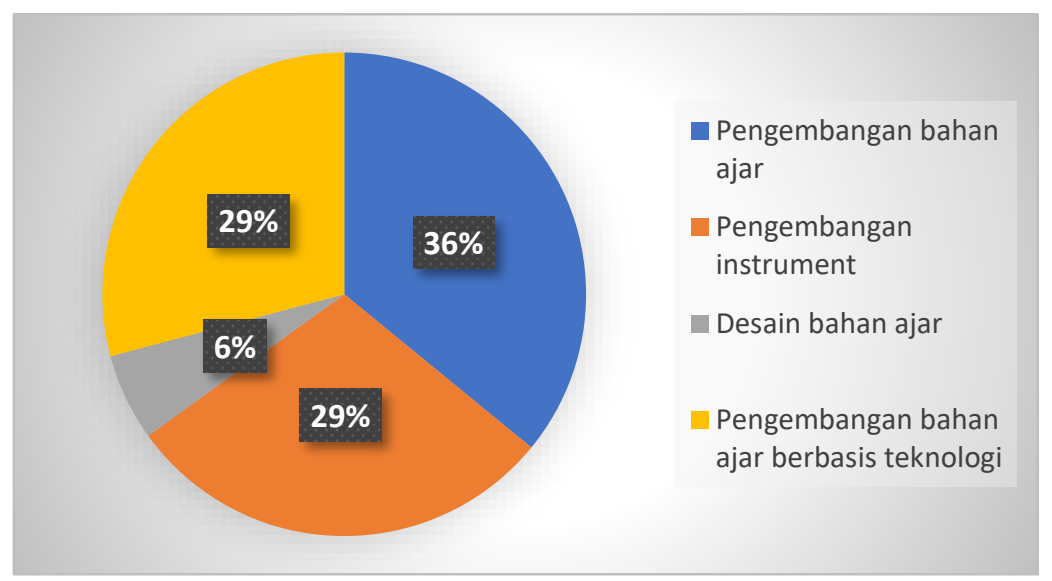

Gambar 1: Diagram persentase jumlah topik penelitian pengembangan bahan ajar tahun 2017

1. Pada tahun 2017 terdapat 31 jumlah topik penelitian, diperoleh $0,74 \%$ jumlah penelitian pengembangan bahan ajar untuk meningkatkan empat keterampilan berbahasa, kemudian terdapat $0,6 \%$ jumlah penelitian dalam pengembangan instrument, $0,12 \%$ jumlah penelitian desain bahan ajar bahasa Arab dan 0,6\% jumlah penelitian pengembangan bahan ajar berbasis teknologi. 
Nurul Aini Baarid \& Kamal Yusuf: Isu Dan Tren Penelitian Pengembangan Bahan Ajar Bahasa Arab Tahun 2017-2020

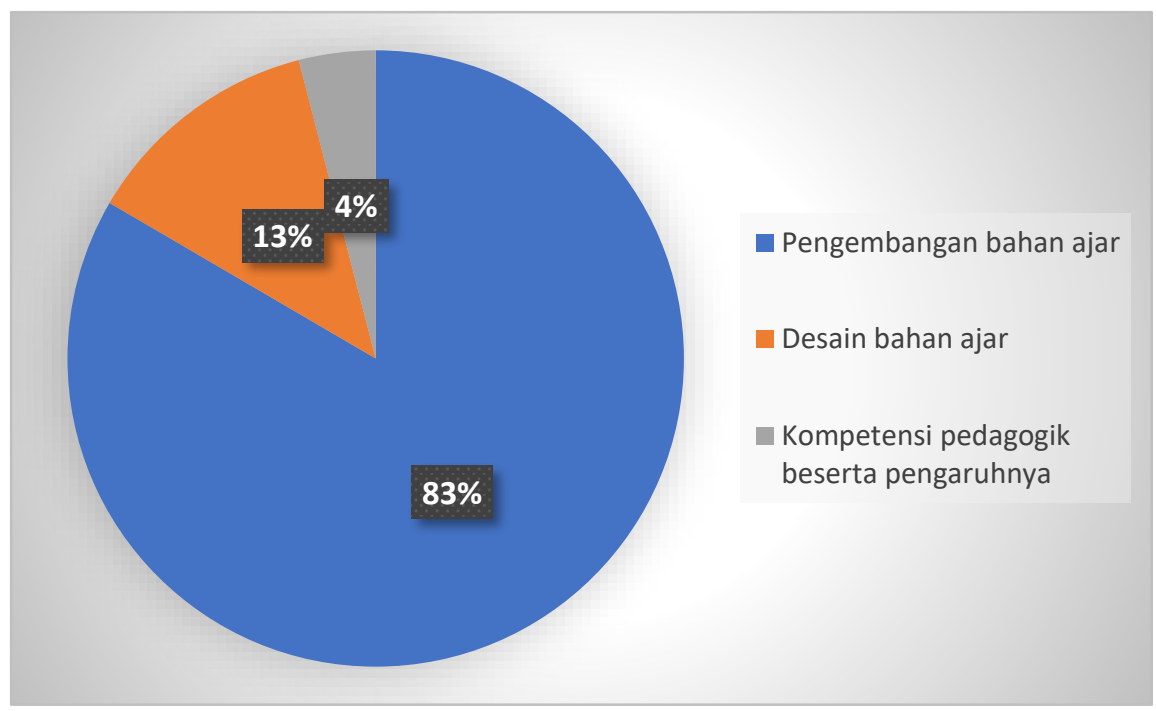

Gambar 2: Diagram persentase jumlah topik penelitian pengembangan bahan ajar tahun 2018

2. Pada tahun 2018 terdapat 24 jumlah topik penelitian, diperoleh $0,83 \%$ jumlah penelitian pengembangan bahan ajar bahasa Arab untuk meningkatkan empat keterampilan berbahasa, selanjutnya terdapat 0,125\% jumlah penelitian desain bahan ajar bahasa Arab dan 0,04\% jumlah penelitian terkait kompetensi pedagogik beserta pengaruhnya. 
Nurul Aini Baarid \& Kamal Yusuf: Isu Dan Tren Penelitian Pengembangan Bahan Ajar Bahasa Arab

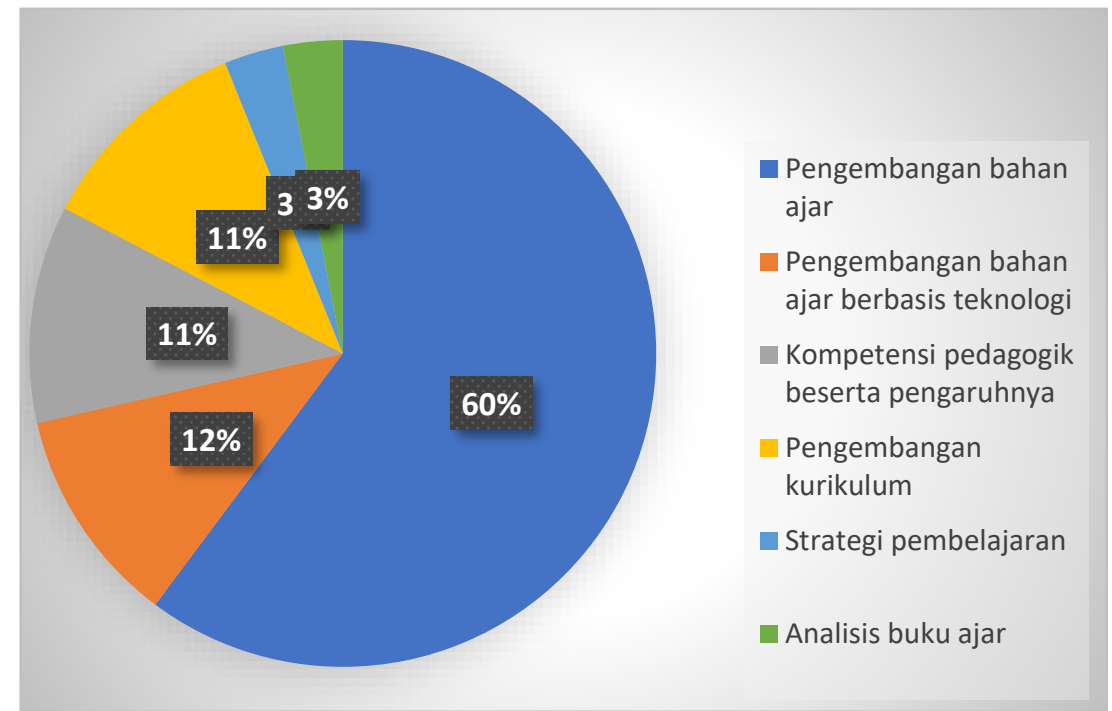

Gambar 3: Diagram persentase jumlah topik penelitian pengembangan bahan ajar tahun 2019

3. Pada tahun 2019 terdapat 27 jumlah topik penelitian, diperoleh $0,59 \%$ jumlah penelitian pengembangan bahan ajar untuk meningkatkan empat keterampilan berbahasa, kemudian diperoleh sebanyak $0,11 \%$ jumlah penelitian berbasis teknologi, dan $0,11 \%$ jumlah penelitian terkait kompetensi pedagogik beserta pengaruhnya, serta $0,11 \%$ untuk penelitian pengembangan kurikulum, 0,03\% untuk jumlah penelitian terkait strategi pembelajaran dan 0,03\% penelitian analisis buku bahan ajar bahasa Arab. 


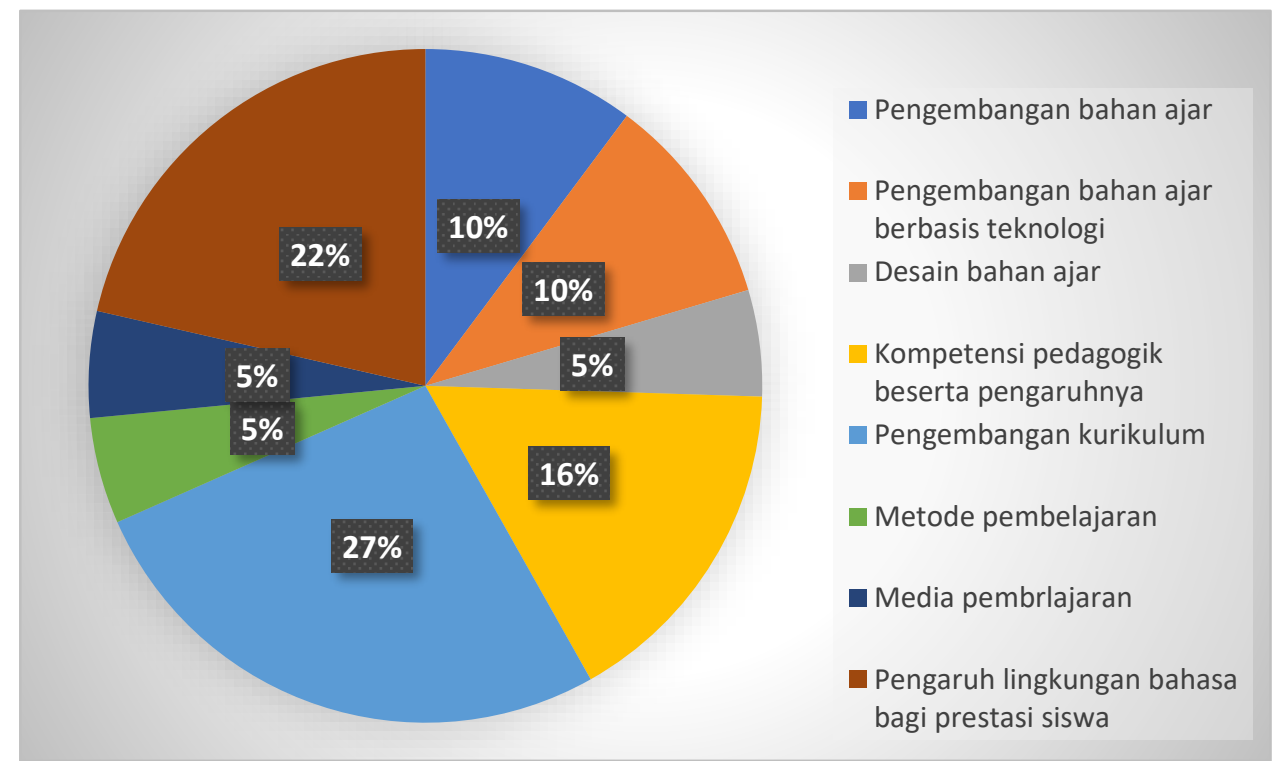

Gambar 4: Diagram persentase jumlah topik penelitian pengembangan bahan ajar tahun 2020

4. Pada tahun 2020 terdapat 19 jumlah topik penelitian, diperoleh $0,1 \%$ jumlah penelitian tentang pengembangan bahan ajar bahasa Arab untuk empat keterampilan berbahasa, dan 0,1\% jumlah penelitian berbasis teknologi, 0,05\% jumlah penelitian terkait desain bahan ajar bahasa Arab, kemudian $0,16 \%$ jumlah penelitian terkait kompetensi pedagogik beserta pengaruhnya, selanjutnya $0,26 \%$ jumlah penelitian terkait kurikulum, $0,05 \%$ jumlah penelitian tentang metode pembelajaran, dan $0,05 \%$ untuk jumlah penelitian tentang media pembelajaran serta 0,21\% jumlah penelitian terhadap pengaruh lingkungan berbahasa bagi prestasi siswa.

\section{PEMBAHASAN}

Dari beberapa topik penelitian yang diperoleh sepanjang empat tahun terakhir yaitu tahun 2017 hingga tahun 2020, diperoleh berbagai macam topik yang berbeda secara rinci, dan terdapat klasifikasi yang sama secara umum. Pada tahun 2017 penelitian yang sering muncul dan menduduki peringkat 
paling atas yaitu penelitian tentang pengembangan bahan ajar bahasa Arab untuk meningkatkan empat keterampilan berbahasa, diperoleh sebesar 0,74\% atau sejumlah 23 topik penelitian terkait dari 31 penelitian yang telah dianalisis, sedangkan jumlah penelitian-penelitian lainnya menunjukkan peringkat dibawahnya, seperti halnya penelitian untuk pengembangan instrument hanya sebesar $0,6 \%$ atau sejumlah 2 topik penelitian saja dan penelitian terkait desain bahan ajar menduduki peringkat dibawahnya sebesar $0,12 \%$ atau sejumlah 4 topik penelitian dan terakhir yaitu topik penelitian berbasis teknologi sebesar $0,6 \%$ atau sebanyak 2 topik penelitian saja. Hal tersebut menunjukkan bahwa tren topik penelitian pengembangan pada tahun 2017 menunjukkan topik penelitian tentang pengembangan bahan ajar bahasa Arab untuk meningkatkan empat keterampilan berbahasa sebagai tren topik atau yang paling sering muncul pada tahun tersebut.

Selanjutnya pada tahun 2018 diperoleh sebesar 0,83\% atau sejumlah 20 dari 24 topik penelitian sebagai tren topik penelitian terkait pengembangan bahan ajar bahasa Arab untuk meningkatkan empat keterampilan berbahasa, selanjutnya pada tahun ini diperoleh sebesar $0,125 \%$ atau sejumlah 3 topik penelitian tentang desain bahan ajar bahasa Arab, dan 0,04\% atau sejumlah 1 topik penelitian terkait kompetensi pedagogik beserta pengaruhnya.

Perkembangan pada tahun 2019 menunjukkan bahwa penelitian pengembangan bahan ajar bahasa Arab untuk meningkatkan empat keterampilan berbahasa menjadi tren penelitian pada tahun ini dan diperoleh sebesar $0,59 \%$ atau sejumlah 16 topik dari 27 jumlah topik penelitian yang dianalisis, selanjutnya yaitu penelitian tentang pembelajaran berbasis teknologi dan penelitian terkait kompetensi pedagogik guru beserta pengaruhnya serta penelitian tentang pengembangan kurikulum masingmasing sebesar $0,11 \%$ atau 3 topik pada masing-masing topik yang dianalisis. Sedangkan pada tahun 2020 yang menjadi tren topik penelitian yaitu penelitian tentang kurikulum pembelajaran bahasa Arab studi perbandingan dan pengembangannya diperoleh sebesar $0,26 \%$ atau sejumlah 5 topik penelitian dari 19 topik yang dianalisis, selanjutnya yaitu penelitian tentang pengaruh lingkungan bahasa terhadap empat keterampilan berbahasa siswa diperoleh sebesar $0,21 \%$ atau 4 jumlah topik penelitian terkait topik yang dianalisis, kemudian penelitian tentang kompetensi pedagogik guru beserta pengaruhnya 
Nurul Aini Baarid \& Kamal Yusuf: Isu Dan Tren Penelitian Pengembangan Bahan Ajar Bahasa Arab Tahun 2017-2020

terhadap prestasi siswa menduduki peringkat ketiga sebagai tren topik pada tahun ini bernilai sebesar $0,16 \%$ atau 3 jumlah topik penelitian, selanjutnya pengembangan bahan ajar bahasa Arab untuk meningkatkan empat keterampilan berbahasa siswa serta penelitian berbasis teknologi untuk pembelajaran bahasa Arab dengan nilai sebesar 0,01\% atau 2 jumlah topik dari 19 topik yang dianalisis, kemudian penelitian tentang desain bahan ajar bahasa Arab, metode pembelajaran dan media pembelajaran masing-masing topik dengan nilai sebesar $0,05 \%$ atau 1 jumlah topik penelitian yang menduduki peringkat terakhir sebagai topik penelitian yang jarang muncul pada tahun ini.

Pada saat ini perkembangan teknologi, informasi dan komunikasi (TIK) telah menjadi kebutuhan bagi seluruh lapisan masyarakat dalam segala aspek kehidupan, termasuk dalam dunia pendidikan serta perkembangan penelitian bahan ajar bahasa Arab di Indonesia. ${ }^{1}$ Selain itu, menjadi tantangan bagi guru di masa depan untuk menciptakan berbagai macam variasi penelitian bahan ajar yang berkualitas. Peningkatan kualitas tidak akan tercapai tanpa partisipasi semua pihak. ${ }^{15}$ Schramm mengemukakan bahwa jenis teknologi, isi dan model instruksional yang digunakan sangat berpengaruh terhadap materi pembelajaran. ${ }^{16}$ Oleh karena itu dibutuhkan sebuah kekreativitasan dan kolaborasi antara guru/dosen dengan mahasiswa dan siswa, juga sesama guru untuk menciptakan dan mengembangkan bahan ajar yang menarik serta dapat diterima dengan senang hati oleh peserta didik. Untuk memfasilitasi generasi milenial yang kritis dan canggih, ${ }^{17}$ maka guru selayaknya memberikan sarana

14 Nuril, Saidna, Irfan and Imam, "Blended Learning Approach in Arabic Teaching For NonNative Speaker Students." EAI: Innovating Research. (Bandung: Proceedings of the $2^{\text {nd }}$ International Conference on Quran and Hadith Studies Information Technology and Media in Conjunction with the $1^{\text {st }}$ International Conference on Islam, Science and Technology, Iconquhas \& Iconist, 2018), page. 1.

مأحمد نور خالض و أمي محمودة، جهود وزارة الشؤون الدينية في إندونيسيا لبناء المدارس الإسلامية

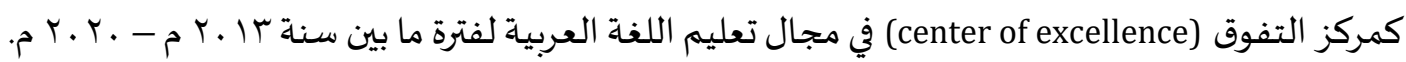

16 Mahyudin, Alwis dan Sri Wahyuni, Pengembangan Model Pembelajaran Bahasa Arab Berbasis Teknologi Informasi dan Komunikasi dalam Dialektika Revolusi Industri 4.0, (Yogyakarta: CV BUDI UTAMA, 2020), h. 3.

17 Indah dan Insana Kamila, "Pentingnya Guru Profesional dalam Mendidik Siswa Milenial untuk Menghadapi Revolusi 4.0." Prosiding Seminar Nasional Pendidikan, (Palembang: Program Pascasarjana Universitas PGRI, 2019), h. 3. 
siswa dalam kegiatan pembelajaran dengan menggunakan smartphone, mengingat pemakaian smartphone yang begitu tinggi oleh peserta didik. ${ }^{18}$ Yaitu pembelajaran kekinian yang memanfaatkan berbagai akses teknologi informasi dan komunikasi dengan memanfaatkan layanan internet, salah satunya adalah bahan ajar berbasis e-book, didalamnya berisi berbagai macam materi ajar bahasa Arab, maka akan sangat efektif dan efisien karena penggunaannya yang sangat praktis, sehingga para siswa dapat membaca dan membuka serta mempelajari sewaktu-waktu dimanapun ia berada apabila ingin mengeksplorasinya, juga pengembangan bahan ajar yang diimplementasikan menggunakan konsep e-learning, akan memberikan solusi yang sesuai dengan kebutuhan siswa dalam berbagai situasi.

Saat ini e-learning hadir dengan sistem pembelajaran elektronik yang biasa dikenal dengan learning management system, virtual learning system atau content management system dan mobile learning. ${ }^{19}$ Dibutuhkan kekreativitasan guru untuk membuat bahan ajar berbasis e-book dan e-learning tersebut agar tampilan dan materi bisa mudah dipahami dan layak untuk dikonsumsi. Tak hanya sebuah pengembangan bahan ajar berbasis e-book dan e-learning sebagai bahan ajar yang diperhitungkan, juga berbagai macam media pembelajaran kekinian lainnya yang dapat mendukung bertumbuhnya tingkat kemahiran siswa dalam berbahasa Arab salah satunya yaitu pembelajaran dengan memanfaatkan model learning vlog yang mampu untuk mengeksplorasi kemampuan siswa/mahasiswa pendidikan bahasa Arab untuk mengembangkan ide dan kreativitas serta kemahiran berbicara siswa/ mahasiswa. Selain learning vlog, bahan ajar yang diaplikasikan menggunakan google site juga dapat menarik minat siswa dan mahasiswa dalam mengembangkan ide kekreatifitasan dan kemampuan mereka dalam berbahasa. Google site merupakan sarana kekinian yang dimanfaatkan untuk

${ }^{18}$ Lilis dan Taufiq, "Media Pembelajaran Pohon Pintar-Kita Berbasis Android Untuk Mata Kuliah Bahasa Arab." IJAZ ARABI: Journal of Arabic Learning 3, no. 1 (2020): h. 3.

19 Mohammad Taufiq, "Adaptation of Addie Instructional Model in Developing Educational Website for Language Learning." Global Journal Al-Thaqafah 8, no. 2 (2018): page. 2. 
membuat situs website. $^{20}$ Layanan google sites diberikan secara gratis, ${ }^{21}$ didalamnya terdapat berbagai macam fitur dan item yang dapat dimanfaatkan untuk menampilkan bahan ajar.

Bahan ajar yang diimplementasikan menggunakan aplikasi Youtube juga memberikan solusi yang tepat untuk memungkinkan pengguna berbagi dan membentuk komunitas sekitar konten. Penggunaan youtube sebagai media pembelajaran mengkondisikan siswa untuk belajar secara mandiri, melalui studi mandiri, siswa menjadi pelaku sekaligus pemikir. Siswa dapat mengakses video dari seorang vlogger yang menyajikan opini mereka tentang sebuah tempat atau benda dalam bentuk lisan/verbal. ${ }^{22}$ Juga berbagai macam pengembangan bahan ajar lainnya yang dapat memanfaatkan akses teknologi, informasi dan komunikasi, dan berbagai macam produk pembelajaran yang berkualitas dalam pengembangan bahan ajar.

Selain itu, tantangan dalam penelitian pengembangan bahan ajar bahasa Arab yang ditujukan di masa depan yaitu penelitian tentang pengembangan bahan ajar yang didalamnya terdapat sebuah materi ajar yang bersifat kolaboratif, misalnya siswa dapat membangun database bersama, dimana setiap kelompok atau kelas bekerja sama melaksanakan proyek, siswa mengeksplorasi suatu fenomena, mengumpulkan data, menulis laporan akhir, dan membagikan hasilnya dengan siswa lain melalui forum kelas (sharing), atau bersama-sama merencanakan dan melaksanakan proyek melalui dokumen dan spreadsheet bersama (kolaborasi) (Blau dan Caspi, 2009).23 Kemudian diaplikasikan menggunakan platform Google Apps, yang diintegrasikan oleh sekolah, sehingga guru dan siswa dapat berbagi ide dengan cepat dan efisien serta dapat diaplikasikan secara offline di dalam kelas ataupun online.

${ }^{20}$ Budi Harsanto, Inovasi Pembelajaran di Era Digital Menggunakan Google Site dan Media Sosial. (Bandung: UNPAD PRESS, 2014), h. 27.

21 Nyoto dan Ridwan, Website Praktis dengan Google Sites, (Jakarta: PT Elex Komputindo, 2010), h. 2.

22 Mahfuz, Aulia, Nurul dan Hamidah, "Penggunaan Vlog dalam Pembelajaran Maharah Kalam." Al-Mi'yar: Jurnal Ilmiah Pembelajaran Bahasa Arab dan Kebahasaaraban 3, no. 1 (2020): h. 7 .

${ }^{23}$ Ina and Tamar, "Digital Competences and Long-Term Integration in School Culture: The Perspective of Elementary School Leaders," Educ Inf Technol, (2016): page. 6. 


\section{SIMPULAN}

Tren penelitian pengembangan bahan ajar bahasa Arab mahasiswa Pascasarjana UIN Sunan Ampel Surabaya sepanjang 4 tahun terakhir sejak tahun 2017 hingga tahun 2020, diperoleh persentasi sebagai berikut.

Penelitian pengembangan bahan ajar bahasa Arab untuk meningkatkan empat keterampilan berbahasa menduduki peringkat pertama sebagai topik penelitian yang paling banyak muncul dengan nilai sebesar $0,6 \%$ atau sejumlah 61 topik dari 101 topik yang dianalisis. Penelitian tentang desain bahan ajar bahasa Arab menduduki peringkat kedua sebagai tren topik dengan nilai sebesar $0,08 \%$ atau sejumlah 8 topik dari 101 topik penelitian yang dianalisis. Penelitian tentang kurikulum pembelajaran bahasa Arab studi perbandingan dan pengembangannya dengan nilai sebesar $0,08 \%$ atau sejumlah 8 topik dari 101 topik penelitian yang dianalisis. Penelitian tentang kompetensi pedagogik dan professional guru beserta pengaruhnya terhadap prestasi siswa dengan nilai sebesar $0,07 \%$ atau sejumlah 7 topik dari 101 topik penelitian yang dianalisis. Penelitian berbasis teknologi untuk pembelajaran bahasa Arab dengan nilai sebesar $0,07 \%$ atau sejumlah7 topik dari 101 topik penelitian yang dianalisis. Penelitian tentang pengaruh lingkungan bahasa terhadap empat keterampilan berbahasa Arab dengan nilai sebesar 0,04\% atau sejumlah 4 topik dari 101 topik penelitian yang dianalisis. Penelitian tentang pengembangan instrumen penilaian dengan nilai sebesar 0,02\% atau sejumlah 2 topik dari 101 topik penelitian yang dianalisis. Penelitian tentang strategi pembelajaran, metode pembelajaran, media pembelajaran dan penelitian berbasis analisis buku masing-masing menduduki peringkat terakhir sebagai topik penelitian yang paling jarang muncul, masing-masing bernilai 0,01\% atau sejumlah 1 topik dari 101 topik penelitian yang dianalisis.

\section{DAFTAR PUSTAKA}

Akhsan dan Ahmadi Muhammadiyah, "Model Belajar dan Pembelajaran Bahasa Arab Generasi Milenial," Lahjah Arabiyah: Jurnal Bahasa Arab dan Pendidikan Bahasa Arab 1, no. 22020.

Budi Harsanto, Inovasi Pembelajaran di Era Digital Menggunakan Google Site dan Media Sosial. (Bandung: UNPAD PRESS, 2014). 
Darisy Syafaah, "Inovasi Pembelajaran Bahasa Arab Pada Prodi Bahasa dan Sastra Arab IAIN Tulungagung dalam Menghadapi Tantangan Era Industri 4.0," Prosiding Konferensi Nasional Bahasa Arab V Malang: Jurusan Sastra Arab Fakultas Sastra Universitas Negeri Malang", 2019.

Devinisi metode analisis deskriptif

adalah:https://elib.unikom.ac.id/files/disk1/699/ibptunikompp-gdlfahmyfadil-34933-8-fahmy un-i.pdf (diakses pada 5 januari 2021).

Digilib UIN Sunan Ampel Surabaya. www.digilib.uinsby.ac.id (diakses pada 16 Oktober 2020).

Erwin Widiasworo, Guru Ideal di Era Digital: Panduan Pemanfaatan Teknologi untuk Guru Masa Kini, (Yogyakarta: Noktah, 2019).

Hesti, Venia, Rofiatus dan Danial, "Video Based Learning Sebagai Trend Media Pembelajaran di Era 4.0." Tarbiyatuna: Jurnal Pendidikan Ilmiah 5, no. 1 2020.

Ina and Tamar, "Digital Competences and Long-Term Integration in School Culture: The Perspective of Elementary School Leaders," Educ Inf Technol, 2016.

Indah dan Insana Kamila, "Pentingnya Guru Profesional dalam Mendidik Siswa Milenial untuk Menghadapi Revolusi 4.0." Prosiding Seminar Nasional Pendidikan, (Palembang: Program Pascasarjana Universitas PGRI, 2019). J. Sumardianta dan Wahyu Kris, Mendidik Generasi $Z$ dan A Marwah Era Milenial Tuah Generasi Digital, (Jakarta: PT Grasindo, 2018).

Lilis dan Taufiq, "Media Pembelajaran Pohon Pintar-Kita Berbasis Android Untuk Mata Kuliah Bahasa Arab." IJAZ ARABI: Journal of Arabic Learning 3, no. 12020.

Mahfuz, Aulia, Nurul dan Hamidah, "Penggunaan Vlog dalam Pembelajaran Maharah Kalam." Al-Mi'yar: Jurnal Ilmiah Pembelajaran Bahasa Arab dan Kebahasaaraban 3, no. 12020.

Mahyudin, Alwis dan Sri Wahyuni, Pengembangan Model Pembelajaran Bahasa Arab Berbasis Teknologi Informasi dan Komunikasi dalam Dialektika Revolusi Industri 4.0, (Yogyakarta: CV Budi Utama, 2020). Mahyuddin Barni, "Tantangan Pendidik di Era Milenial," Transformatif: Jurnal Islamic Studies 3, no. 012019. 
Mohammad Taufiq, "Adaptation of Addie Instructional Model in Developing Educational Website for Language Learning." Global Journal Al-Thaqafah 8, no. 22018.

Nuril, Saidna, Irfan and Imam, "Blended Learning Approach in Arabic Teaching For Non-Native Speaker Students." EAI: Innovating Research. (Bandung: Proceedings of the $2^{\text {nd }}$ International Conference on Quran and Hadith Studies Information Technology and Media in Conjunction with the $1^{\text {st }}$ International Conference on Islam, Science and Technology, Iconquhas \& Iconist, 2018).

Nyoto dan Ridwan, Website Praktis dengan Google Sites, (Jakarta: PT Elex Komputindo, 2010).

Saipul dan Bahruddin, Metode Penelitian Kuantitatif Aplikasi dalam Pendidikan, (Yogyakarta: Deepublish CV Budi Utama, 2014).

Slamet dan Aglis, Metode Riset Penelitian Kuantitatif, Penelitian di Bidang Manajemen, Teknik, Pendidikan dan Eksperimen, (Yogakarta: CV Budi Utama, 2020).

Yusnaini dan Slamet, "Era Revolusi Industri 4.0: Tantangan dan Peluang dalam Upaya Meningkatkan Literasi Pendidikan." Prosiding seminar nasional pendidikan Program Pascasarjana Universitas PGRI Palembang, 2019).

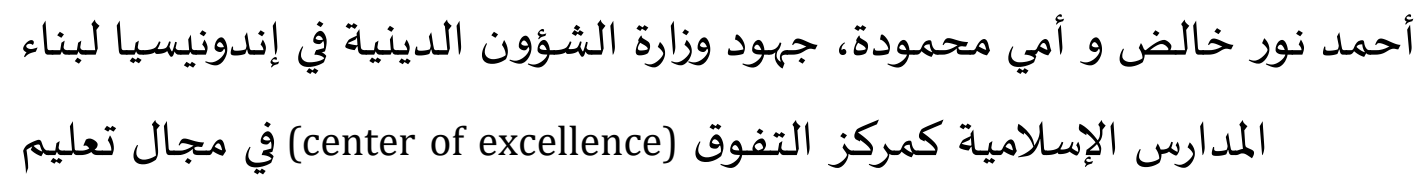

$$
\text { اللغة العربية لفترة ما بين سناة سا .r م - . . . م م. }
$$


Nurul Aini Baarid \& Kamal Yusuf: Isu Dan Tren Penelitian Pengembangan Bahan Ajar Bahasa Arab Tahun 2017-2020 